\title{
Photocatalytic Degradation of Phenol Using Nb-loaded ZnO Nanoparticles
}

\author{
Viruntachar Kruefu, ${ }^{1,5}$, Hathaithip Ninsonti ${ }^{2}$, Natda Wetchakun ${ }^{3}$, \\ Burapat Inceesungvorn $^{2}$, Pusit Pookmanee ${ }^{4,5}$ and Sukon Phanichphant ${ }^{6}$ \\ 1 Program in Materials Science, Faculty of Science, Maejo University, Chiang Mai 50290, Thailand \\ 2 Department of Chemistry, Faculty of Science, Chiang Mai University, Chiang Mai 50200, Thailand \\ 3 Department of Physic and Materials Science, Faculty of Science, Chiang Mai University, Chiang Mai \\ 50200, Thailand \\ 4 Program in Applied Chemistry, Faculty of Science, Maejo University, Chiang Mai 50290, Thailand \\ 5 Nanoscience and Nanotechnology Research Laboratory (NNRL), Faculty of Science, Maejo University, \\ Chiang Mai 50290, Thailand \\ 6 Materials Science Research Center, Faculty of Science, Chiang Mai University, Chiang Mai 50200, \\ Thailand \\ E-mail: v_viruntachar@hotmail.com*
}

\begin{abstract}
Niobium-loaded Zinc Oxide nanoparticles (Nb-loaded ZnO NPs) in the range of 20 and $40 \mathrm{~nm}$ were synthesized by Flame Spray Pyrolysis (FSP) technique. The crystalline phase, morphology and size of the nanoparticles were characterized by X-ray diffraction (XRD), transmission electron microscopy (TEM) and UV-vis spectroscopy. The specific surface area of the nanoparticles was measured by nitrogen adsorption (BET analysis). The unloaded $\mathrm{ZnO}$ and Nb-loaded $\mathrm{ZnO}$ NPs were found to have the clear spherical, hexagonal and rod-like morphologies. In this study, the photocatalytic activities of unloaded $\mathrm{ZnO}$ and Nb-loaded $\mathrm{ZnO} \mathrm{NPs}$ were determined by studying the mineralization of phenol under UV light illumination. The results indicated that all $\mathrm{Nb}$ loaded $\mathrm{ZnO}$ NPs have better photocatalytic activity than the unloaded $\mathrm{ZnO}$ nanoparticles. It was found that, $0.50 \mathrm{~mol} \% \mathrm{Nb}$-loaded $\mathrm{ZnO} \mathrm{NPs}$ exhibited the fastest response to the degradation of phenol.
\end{abstract}

Keywords: Nb-loaded ZnO, flame spray pyrolysis, photocatalysis, phenol.

ENGINEERING JOURNAL Volume 16 Issue 3

Received 21 November 2011

Accepted 29 February 2012

Published 1 July 2012

Online at http://www.engj.org/

DOI:10.4186/ej.2012.16.3.91

This paper is based on the poster presentation at the German-Thai Symposium on Nanoscience and Nanotechnology 2011_Green Nanotechnology of the Future, GTSNN 2011, in Nakbon Ratchasima, Thailand, 13-16 September 2011. 


\section{Introduction}

Phenols and phenolic compounds often exist in the wastewaters of many industries such as herbicide, paper mill and fungicide production plants, etc. [1]. Many of them are very toxic, showing adverse effects on animal and plants. Photocatalysis has been proven to be a plausible technique to decontaminate phenolic waste-water as complete mineralization has been successfully achieved under a variety of conditions [2]. It has widely reported that phenol can be degraded by photocatalytic processes using $\mathrm{ZnO}$ as catalysts and oxygen as electron acceptor [3].

$\mathrm{ZnO}$ is known to be one kind of the important photocatalysts because of its unique advantages, such as its low price, high photocatalytic activity and nontoxicity, that has attracted a great deal of attention with respect to the degradation of various pollutants due to its high photosensitivity and stability [4]. Among these properties, the degradation of the pollutants catalyzed by $\mathrm{ZnO}$ has been studied widely [5]. It has also suggested that $\mathrm{ZnO}$ is a low cost alternative photocatalyst to $\mathrm{TiO}_{2}$ for photodegradation of organics in aqueous solutions [6-8], as it has a similar band gap energy (3.2 eV) [9], with higher photocatalytic efficiencies was reported [10-11]. However, the photocatalytic properties of $\mathrm{ZnO}$ for the degradation of pollutants are directly related to their preparation e.g. particle size, morphology and dopant concentrations. It is well known that the surface characteristic of $\mathrm{ZnO}$ determined by the different fabrication process will influence the photocatalytic property as well as the final degradation efficiency.

Flame spray pyrolysis (FSP) is a cost-effective and versatile process for controlling the production of nanoparticles materials. This process has been demonstrated as one-step, suitable for dry synthesis of high surface area, and highly efficient for noble metal laden catalysts. These advantages of FSP prompted us to apply for production of unloaded $\mathrm{ZnO}$ and $\mathrm{Nb}$-loaded $\mathrm{ZnO} \mathrm{NPs}$ for photocatalyst in photodegradation of various organic solutions. The presence of the doping metal ions in the $\mathrm{ZnO}$ crystalline matrix significantly affects the photocatalytic activity, charge carrier recombination rate and interfacial electron transfer rate [12]. Generally speaking, the metal ions used as dopants are often the transition metal ions, e.g., Co [13], Mn [14], Ti [15], La [16], Fe [17], Ni [18], N [19] and so forth. However, no previous work has been reported on the photocatalytic photodegradation of organic contaminants by Nb-loaded ZnO NPs. In the present article, we synthesized and report on the photocatalytic decomposition behavior of phenol on $\mathrm{ZnO}$ nanoparticles and $\mathrm{Nb}-$ loaded $\mathrm{ZnO} \mathrm{NPs}$ under UVA irradiation.

\section{Experimental}

\subsection{Preparation of the Catalyst}

The $\mathrm{ZnO}$ and Nb-loaded $\mathrm{ZnO} \mathrm{NPs}$ with different $\mathrm{Nb}$ contents were synthesized by FSP technique [20-22]. The precursor solution were prepared from Zinc naphthenate (Aldrich, $8 \mathrm{wt} \% \mathrm{Zn}$ ) and niobium (V) ethoxide (Aldrich, 99.999\%) diluted in toluene/methanol (70/30 vol\%). Precursor solutions were fed into a FSP reactor by a syringe pump with a rate of $5 \mathrm{ml} / \mathrm{min}$ through the inner reactor capillary while $5 \mathrm{l} / \mathrm{min} \mathrm{O}_{2}$ is being dispersed ( $5 / 5$ flame). The gas flow rates of methane and $\mathrm{O}_{2}$ supporting flamelets were 1.19 , and $2.46 \mathrm{l} / \mathrm{min}$, respectively. The pressure drop at the capillary tip was kept constant at 1.5 bars by adjusting the orifice gap area at the nozzle. The experimental setup for flame-made unloaded $\mathrm{ZnO}$ and $\mathrm{Nb}$-loaded $\mathrm{ZnO}$ NPs is presented in Fig. 1. The flame height was about 10-11 cm and showed an orange-yellowish flame appearance. After evaporation and combustion of precursor droplets, particles are formed by nucleation, condensation, coagulation and coalescence then resulting in $\mathrm{Nb}$ deposited on $\mathrm{ZnO}$ support. Finally, the nanopowders were collected on glass microfiber filters (Whatmann GF/D, $25.7 \mathrm{~cm}$ in diameter) with the aid of a vacuum pump. 


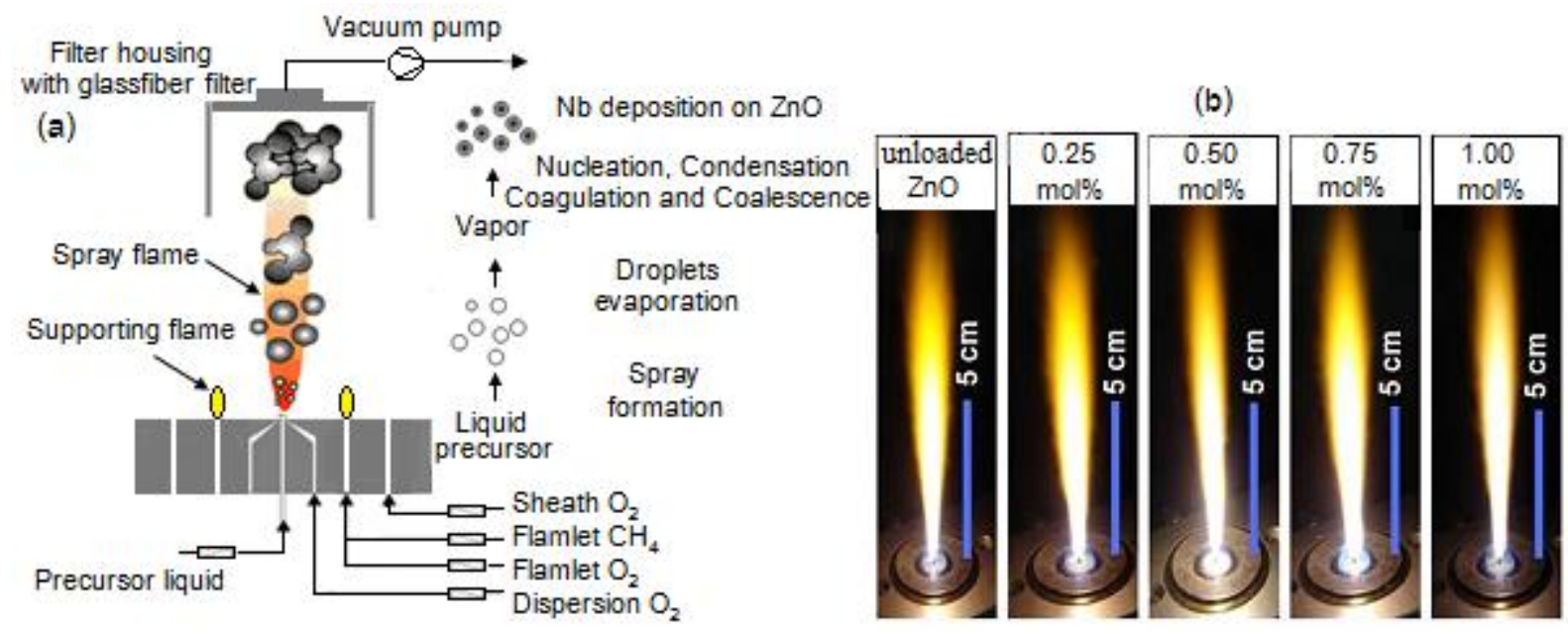

Fig. 1. (a) experimental setup for the synthesis of Nb-loaded ZnO NPs and (b) spray flame (0.5 M zinc naphthenate and Niobium (V) ethoxide in toluene/methanol: 70/30 vol\%) of unloaded $\mathrm{ZnO}$, $0.25,0.50,0.75$ and $1.00 \mathrm{~mol} \%$ Nb-loaded ZnO NPs [20-22].

\subsection{Characterization of the Catalyst}

The phase and crystallinity of the flame-made nanopowders were analyzed by X-ray diffraction spectroscopy using $\mathrm{CuK} \alpha$ radiation at $2 \theta=20-80^{\circ}$ with a step size of $0.06^{\circ}$ and a scanning speed of $0.72^{\circ} / \mathrm{min}$. The morphology and size of the nanoparticles were characterized by scanning electron microscopy (SEM) and transmission electron microscopy (TEM). The specific surface area of the nanoparticles was measured by nitrogen adsorption at $150^{\circ} \mathrm{C}$, using Brunauer-Emmett-Teller (BET) analysis. The optical properties of $\mathrm{ZnO}$ samples were evaluated in term of UV-Vis absorption spectra (Varian Cary 50 UV-Vis spectrophotometer) at room temperature.

\subsection{Photocatalytic Measurement}

The photocatalytic activities of prepared samples were evaluated by photodegradation of phenol solution under the similar conditions. The experiments were carried out in a spiral photoreactor. The light was provided from the middle of the spiral photoreactor by NEC black light blue $20 \mathrm{~W}$ (T10) without filter giving the strongest emission light in the wavelength of $360 \mathrm{~nm}$. The suspension of $\mathrm{ZnO}$ or Nb-loaded $\mathrm{ZnO}$ sample, $(1 \mathrm{~g} / \mathrm{l})$ was dispersed in an ultrasonic bath for $20 \mathrm{~min}$ before being added into the spiral photoreactor. Prior to catalytic testing, carbon atom contaminated in the catalyst was eliminated by circulating the solution through the spiral photoreactor until the photoreaction reached constant equilibrium under UVA light illumination. Then organic substance (equivalent to $500 \mu \mathrm{g}$ of carbon ( $\mu \mathrm{g} \mathrm{C}$ ) was added into the spiral photoreactor. The carbon dioxide generated by degradation of organic compound was determined via conductivity measurement using EUTECH PC 5500. The photocatalytic activity of the prepared samples was compared on the basis of the rate of carbon dioxide generation or mineralization.

\section{Results and Discussion}

\subsection{Structure and Morphology of Nb-Loaded $\mathrm{ZnO}$ Nanoparticles}

Nb-loaded ZnO NPs were synthesized by FSP from Zinc naphthenate and niobium (V) ethoxide precursors under $5 / 5$ (precursor/oxygen) flame condition. The phase and crystallinity of unloaded $\mathrm{ZnO}$ and 0.25-1.00 mol\% Nb-loaded ZnO NPs were analyzed by XRD spectroscopy. The XRD patterns showed that $\mathrm{ZnO}$ NPs were highly crystalline, and the peaks can be confirmed to be hexagonal structure of $\mathrm{ZnO}$ (JCPDS No. 89-0510 [23]) that shown in Fig. 2. Other crystalline phases such as $\mathrm{NbO}, \mathrm{NbO}_{2}, \mathrm{Nb}_{2} \mathrm{O}_{5}$ or $\mathrm{Nb}$ metal was not observed in the XRD patterns. This is probably due to the presence of highly dispersed 
niobium species, thus the crystallite size is too small and the measurement is under detection limit of the instrument.

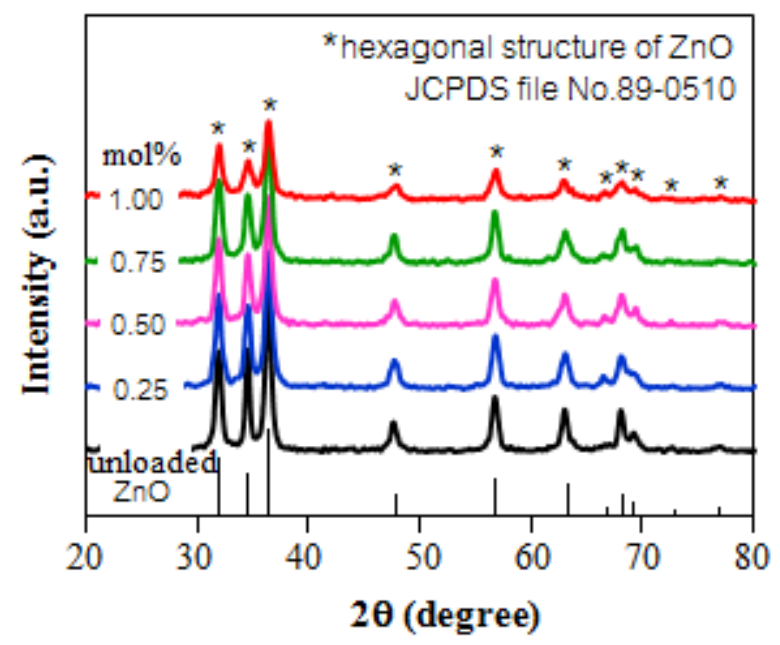

Fig. 2. XRD patterns of the flame-made (5/5) unloaded $\mathrm{ZnO}$ and Nb-loaded $\mathrm{ZnO}$ NPs with different $\mathrm{Nb}$ concentrations.

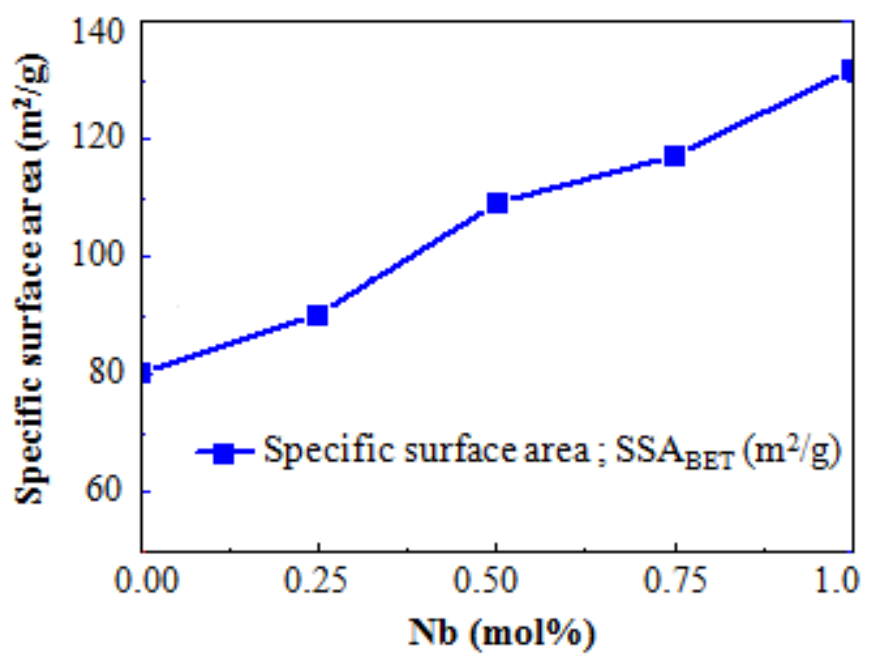

Fig. 3. The specific surface area ( $S S A_{\mathrm{BET}}$ ) of unloaded $\mathrm{ZnO}$ and $0.25-1 \mathrm{~mol} \%$ Nb-loaded $\mathrm{ZnO} N$ Ps.

The specific surface area ( $\mathrm{SSA}_{\mathrm{BET}}$ ) of $\mathrm{ZnO}$ samples were measured by nitrogen adsorption as shown in Fig. 3 and the results clearly showed that $\mathrm{SSA}_{\mathrm{BET}}$ increased with increasing $\mathrm{Nb}$ concentration from 0.25 to $1.00 \mathrm{~mol} \%$. Accurate particle size and morphology of Nb-loaded $\mathrm{ZnO}$ were further confirmed by TEM images.

The absorption spectra of unloaded $\mathrm{ZnO}$ and Nb-loaded $\mathrm{ZnO}$ NPs were shown in Fig. 4. It was found that the absorption spectra of $\mathrm{ZnO}$ loaded with $\mathrm{Nb}$ at different ratio were quite similar to that of unloaded $\mathrm{ZnO}$. The absorption edges of all samples were about $375 \mathrm{~nm}$ which corresponds to the band-gap energy of about $3.2 \mathrm{eV}$. The UV-Vis results indicated that $\mathrm{Nb}$ loading did not significantly affect the $\mathrm{ZnO}$ structure in this study. 


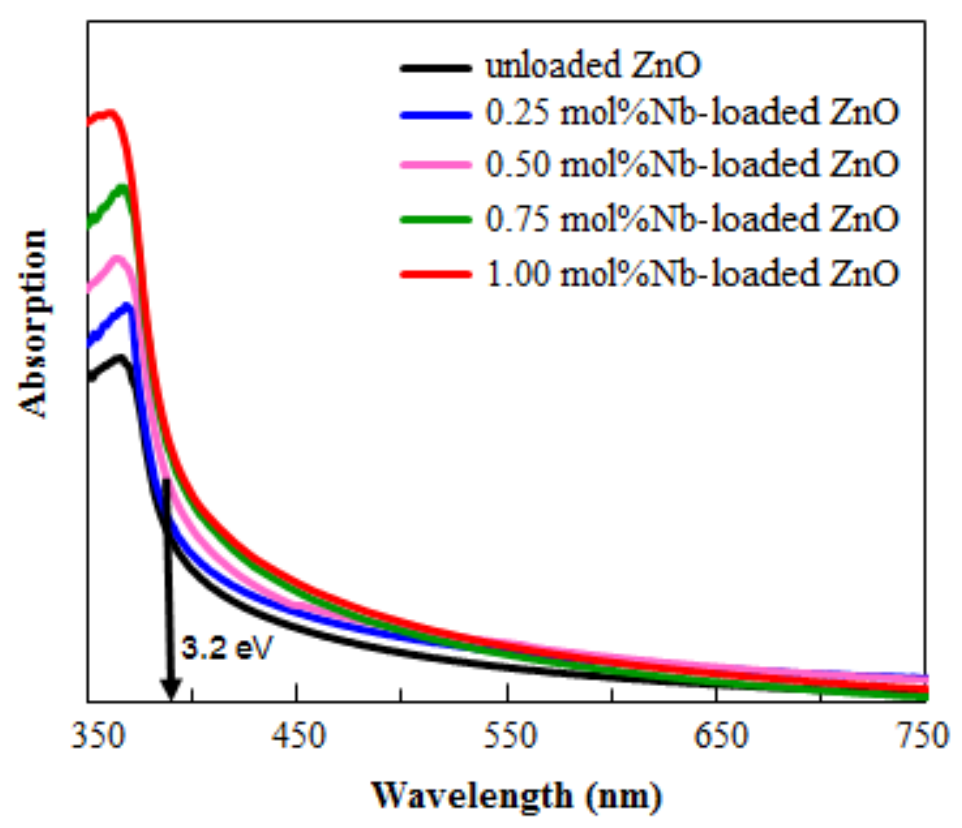

Fig. 4. Absorption spectra of unloaded $\mathrm{ZnO}$ and $\mathrm{Nb}$-loaded $\mathrm{ZnO}$ NPs with different $\mathrm{Nb}$ concentration.

TEM bright-field image and EDS analysis of FSP-made unloaded $\mathrm{ZnO}$ and Nb-loaded $\mathrm{ZnO}$ nanoparticles with $1.00 \mathrm{~mol} \%$ metal loadings are shown in Fig. 5. Spherical $\mathrm{ZnO}$ nanoparticles $(5-20 \mathrm{~nm})$ along with a few nanorods ranging from $5-20 \mathrm{~nm}$ in width and $20-40 \mathrm{~nm}$ in length were found according to the TEM results. The chemical elements of unloaded $\mathrm{ZnO}$ and $1.00 \mathrm{~mol} \%$ of Nb-loaded $\mathrm{ZnO}$ NPs were analyzed from EDS spectra. The signal of EDS spectra corresponded to Nb, Zn and O elements.

\subsection{Photocatalytic Activity and Mechanism}

The percent of degradation of phenol as a function of time using unloaded and Nb-loaded $\mathrm{ZnO} \mathrm{NPs}$ photocatalyst containing $0.25,0.50$ and $1.0 \mathrm{~mol} \% \mathrm{Nb}$ were shown in Fig. 6. All curves of phenol degradation with different concentrations of $\mathrm{Nb}$ in $\mathrm{ZnO}$ photocatalyst looked similar to "S" character. It can be seen from Fig. 7 that $0.50 \mathrm{~mol} \%$ Nb-loaded ZnO NPs shows the highest photocatalytic activity among all samples and took shortest time to complete phenol degradation process. The results clearly suggested that the photocatalytic activity of $\mathrm{ZnO}$ NPs is greatly improved by loading an appropriate amount of $\mathrm{Nb}$. The optimal amount of $\mathrm{Nb}$ was found to be $0.50 \mathrm{~mol} \%$ for degradation of the organic compound tested in this research. It was also found in this work that increasing $\mathrm{Nb}$ loading results in an enlarged surface area of the Nb-loaded $\mathrm{ZnO}$ photocatalysts. However, the increase of surface area is likely not the main factor affecting the photocatalytic activity of Nb-loaded $\mathrm{ZnO}$ in our study. This could be supported by the fact that the surface area of $1 \mathrm{~mol} \% \mathrm{Nb}$-loaded $\mathrm{ZnO} \mathrm{NPs}$ is higher than $0.5 \mathrm{~mol} \% \mathrm{Nb}$ loaded $\mathrm{ZnO}$ NPs, however its photocatalytic activity is lower. Other factors that could affect photocatalytic efficiency are such as the availability of active sites, crystalline structure, pore size and number/nature of trapped sites [24, 25].

Enhanced photocatalytic efficiencies upon loading the semiconductor photocatalysts with Niobium were previously observed in the works of Yang et al. [26] and Li et al. [27]. In those works, an increased photocatalytic degradation of dyes obtained from $\mathrm{Nb}$-doped $\mathrm{TiO}_{2}$ was ascribed to the extended light absorption range and the suppression of electron hole pair recombination upon $\mathrm{Nb}$ loading. According to the literatures and the fact that Niobium acting as an electron trap [28], an enhanced photocatalytic activity of Nb-loaded $\mathrm{ZnO} \mathrm{NPs}$ found in our study was likely ascribed to a decrease of electron-hole pair recombination and thus promoting the photocatalytic activity of $\mathrm{TiO}_{2}$ [24, 27]. If the amount of $\mathrm{Nb}$ loading is higher than the optimal value, the activity of $\mathrm{ZnO} N P s$ will begin to go down inversely. This is probably because an excess amount of $\mathrm{Nb}$ may become the center for recombining photoinduced electron and hole pairs [24]. 

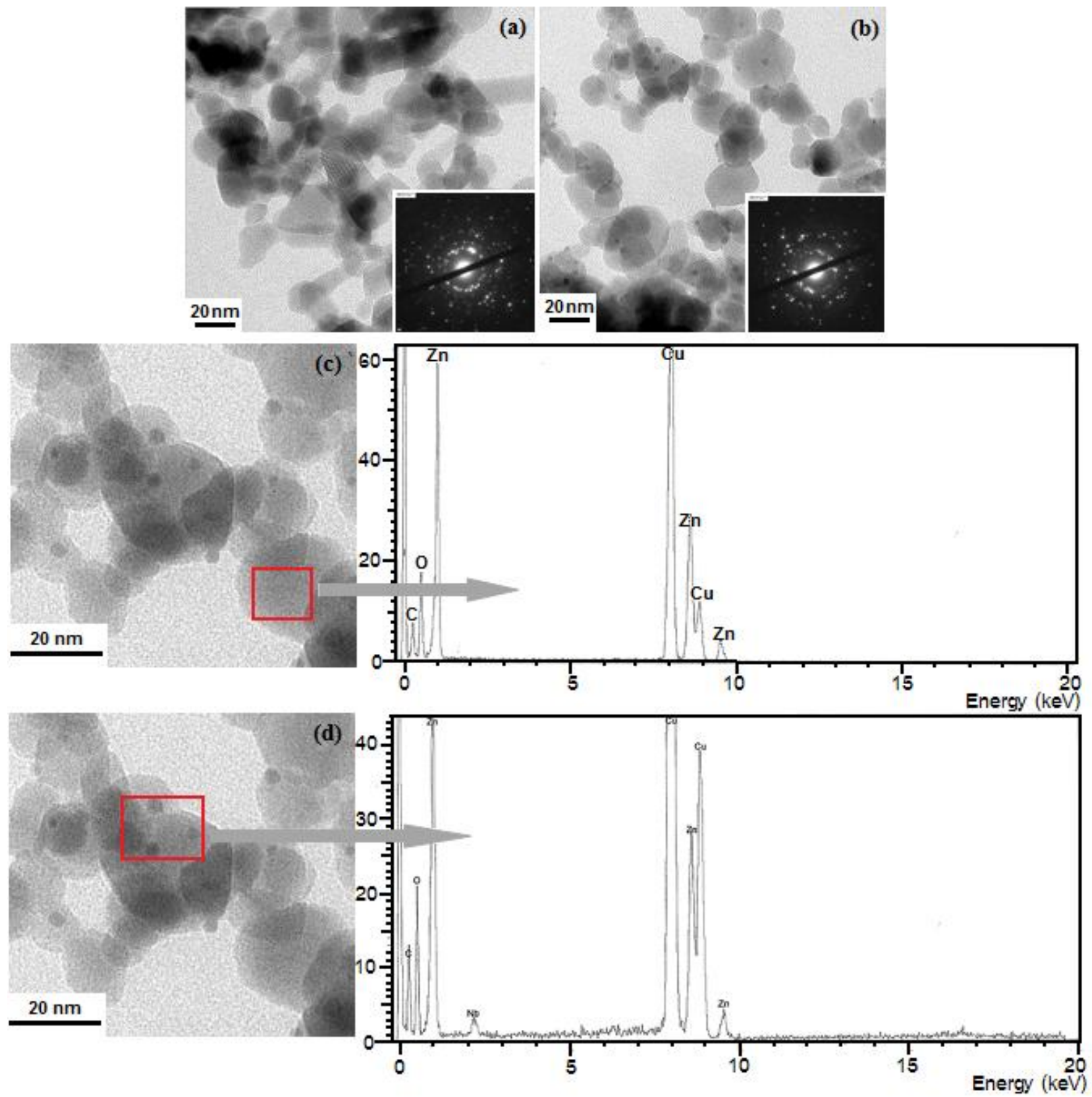

Fig. 5. TEM bright-field image of (a) unloaded $\mathrm{ZnO}$, (b) $1.00 \mathrm{~mol} \% \mathrm{Nb}$-loaded $\mathrm{ZnO} \mathrm{NPs}$ and (c,d) TEM bright-field image and EDS analysis of $1.00 \mathrm{~mol} \%$ Nb-loaded $\mathrm{ZnO} \mathrm{NPs}$ to confirm the $\mathrm{Nb}$ deposited on $\mathrm{ZnO}$ support. 


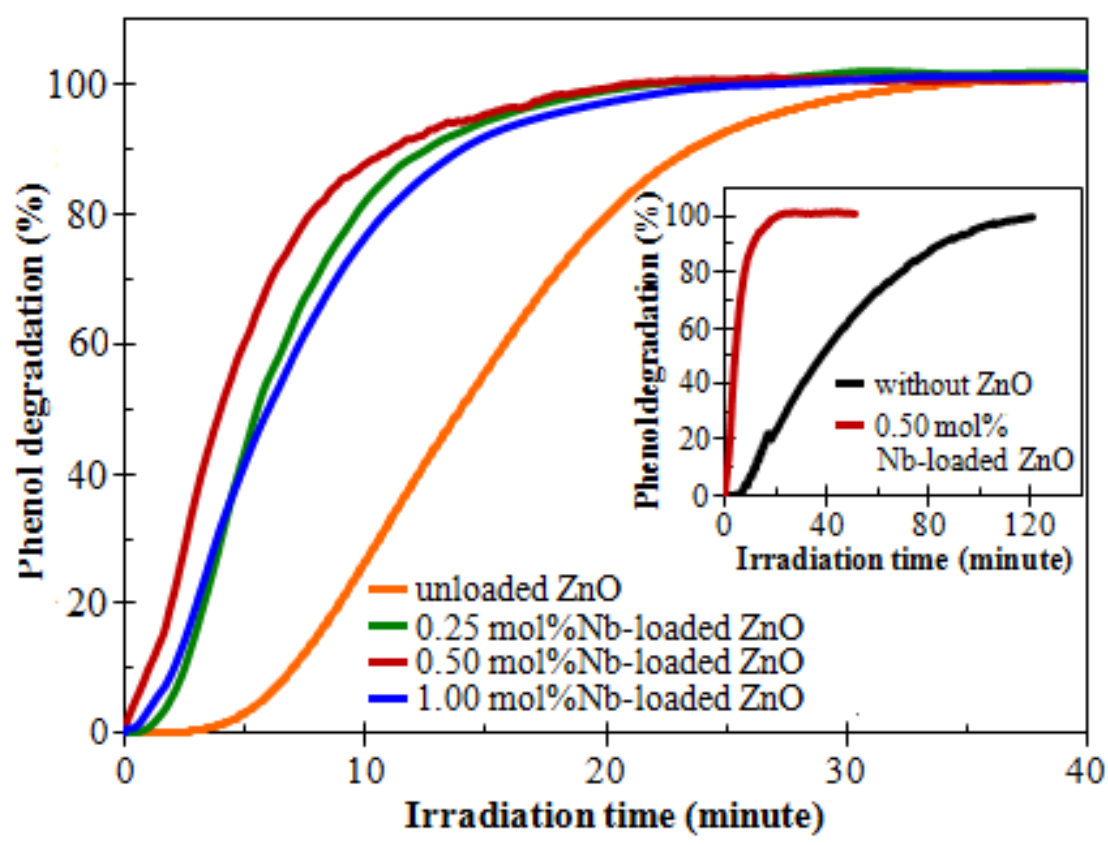

Fig. 6. The percentage of phenol degradation using unloaded $\mathrm{ZnO}$ and Nb-loaded $\mathrm{ZnO} \mathrm{NPs}$ photocatalyst containing $0.25,0.50$ and $1.0 \mathrm{~mol} \% \mathrm{Nb}$. The inset shows the comparison of phenol degradation percentage between $0.50 \mathrm{~mol} \% \mathrm{Nb}$-loaded $\mathrm{ZnO}$ and phenol photolysis (without $\mathrm{ZnO}$ NPs photocatalyst).

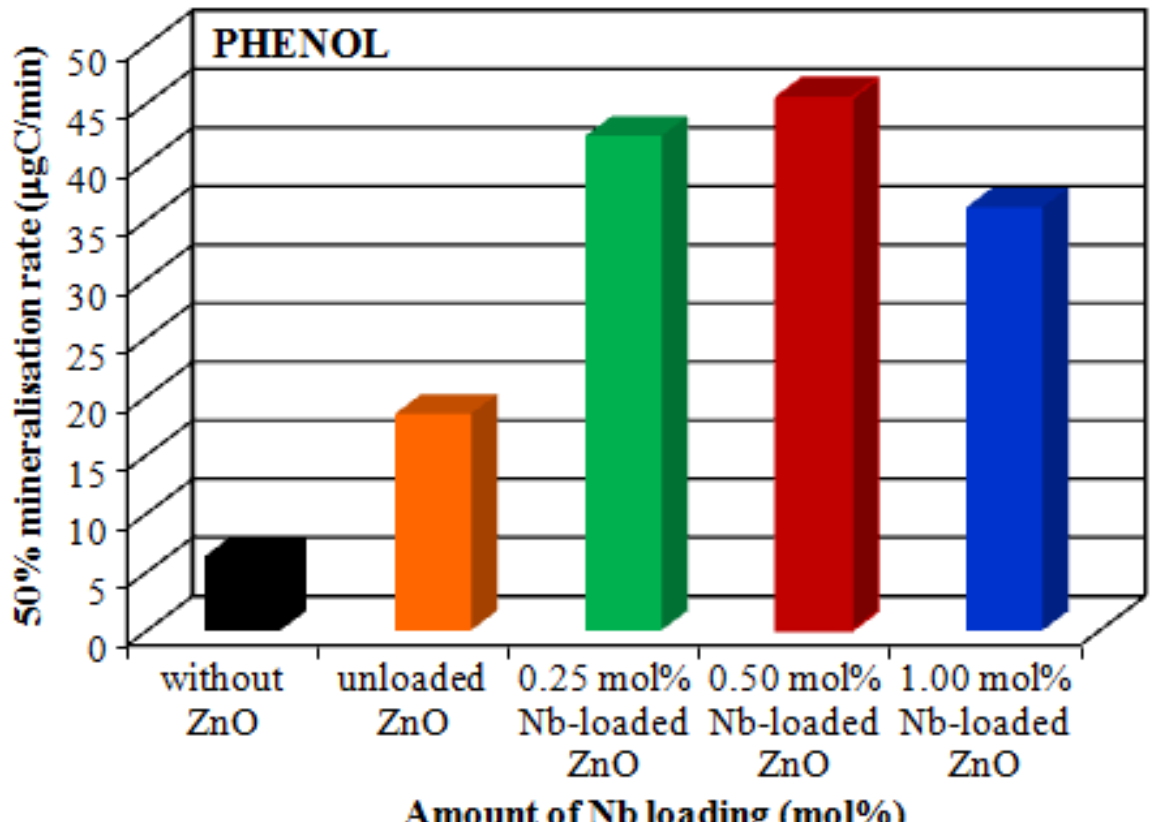

Fig. 7. Photocatalytic degradation rate of phenol on Nb-loaded ZnO NPs with different Nb loading. 
Table 1. The comparison of time for completing the degradation process of phenol with different types of photocatalyst.

\begin{tabular}{lr}
\hline Photocatalyst type & $\begin{array}{r}\text { Completed phenol } \\
\text { degradation time (min) }\end{array}$ \\
\hline Without $\mathrm{ZnO}$ & 108 \\
Unloaded $\mathrm{ZnO}$ & 29.93 \\
$0.25 \mathrm{~mol} \% \mathrm{Nb}-$ loaded $\mathrm{ZnO}$ & 20.07 \\
$0.50 \mathrm{~mol} \% \mathrm{Nb}-$ loaded $\mathrm{ZnO}$ & 18.40 \\
$1.00 \mathrm{~mol} \% \mathrm{Nb}-$ loaded $\mathrm{ZnO}$ & 22.33 \\
\hline
\end{tabular}

\section{Conclusions}

Nb-loaded ZnO NPs were successfully synthesized via the FSP technique by using the mixture of Zinc naphthenate and niobium (V) ethoxide as a precursor. The particle size of Nb-loaded $\mathrm{ZnO}$ NPs was found to decrease with increasing the $\mathrm{Nb}$ content. It was found that an appropriate amount of $\mathrm{Nb}$ loading $(0.50$ $\mathrm{mol} \%$ in this study) over $\mathrm{ZnO}$ nanoparticles could greatly enhance the photocatalytic degradation of phenol tested in this study. This improved activity could be due to $\mathrm{Nb}$ particles acting as electron traps, retarding the recombination of electron-hole pairs, and thus, promoting the photocatalytic activity.

\section{Acknowledgements}

The authors gratefully acknowledge Program in Materials Science, Faculty of Science, Maejo University, Thailand; Nanoscience and Nanotechnology Research Laboratory (NNRL), Maejo University, Thailand; the Royal Thai Government, Ministry of Science and Technology, Thailand; Materials Science Research Center, Faculty of Science, Chiang Mai University, Thailand and Nanoscience and Nanotechnology Laboratory (NRL), Chiang Mai University, Thailand.

\section{References}

[1] C. Baird, Environmental Chemistry, 2nd ed. New York: Freeman, 1998, pp.331-332.

[2] N. Serpone, R. Terzian, C. Minero, and E. Pelizzetti, "Photosensitive metal- organic systems," J. Am. Chem. Soc., vol. 238, pp. 281-314, May 1993.

[3] N. Morales-Flores, U. Pal, and E. Sanchez Mora, "Photocatalytic behavior of $\mathrm{ZnO}$ and $\mathrm{Pt}$ incorporated $\mathrm{ZnO}$ nanoparticles in phenol degradation," Applied Catalysis A: General, vol. 394, no. 1-2, pp. 269-275, Feb. 2011.

[4] K. Byrappa, A. K. Subramani, S. Ananda, K. M. Lokanatharai, M. H. Sunitha, B. Basavalingu, and K. Soga, "Impregnation of $\mathrm{ZnO}$ onto activated carbon under hydrothermal conditions and its photocatalytic properties," J. Mater. Sci., vol. 41, pp. 1355-1362, May 2006.

[5] F. Xu, P. Zhang, A. Navrotsky, Z. Y. Yuan, T. Z. Ren, M. Halasa, and B. L. Su, "Hierarchically assembled porous $\mathrm{ZnO}$ nanoparticles: synthesis, surface energy, and photocatalytic activity," Chem. Mater., vol. 19, no. 16, pp. 5680-5686, Oct. 2007.

[6] U. Černigoj, U. L. Štangar, P. Trebše, U.O. Krašovec, and S. Gross, "Photocatalytically active $\mathrm{TiO}_{2}$ thin films produced by surfactant-assisted sol-gel processing," Thin Solid Films, vol. 495, no. 1-2, pp. 327-332, Jan. 2006.

[7] H. Yu, K. Zhang, and C. Rossi, "Theoretical study on photocatalytic oxidation of VOCs using nano$\mathrm{TiO}_{2}$ photocatalyst," J. Photoch. Photobiol. A., vol. 188, no. 1, pp. 65-83, Apr. 2007.

[8] A. F. Caliman, C. Cojocaru, A. Antoniadis, and I. Poulios, "Optimized photocatalytic degradation of Alcian Blue 8 GX in the peresence of $\mathrm{TiO}_{2}$ suspensions," J. Hazard. Mater., vol. 144, no. 1-2, pp. 265 273, June 2007.

[9] C. Lizama, J. Freer, J. Baeza, and H. D. Mansilla, "Optimized photodegradation of Reactive Blue 19 on $\mathrm{TiO}_{2}$ and $\mathrm{ZnO}$ suspensions," Catal. Today, vol. 76, no. 2-4, pp. 235-246, Nov. 2002.

[10] F. Peng, H. Wang, H. Yu, and S. Chen, "Preparation of Ag-sensitized $\mathrm{ZnO}$ and its photocatalytic performance under visible light irradiation," Mater. Res. Bull., vol. 41, pp. 2123-2129, 2006. 
[11] S. K. Kansal, M. Singh, and D. Sud, "Studies on photodegradation of two commercial dyes in aqueous phase using different photocatalysts," J. Hazard. Mater, vol. 141, no. 3, pp. 581-590, Mar. 2007.

[12] G. Marci, V. Augugliaro, M. J. Lopez-Munoz, C. Martin, L. Palmisano, V. Rives, M. Schiavello, R. J. D. Tilley, and A. M. Venezia, "Preparation characterization and photocatalytic activity of polycrystalline $\mathrm{ZnO} / \mathrm{TiO}_{2}$ systems. 1. Surface and bulk characterization," J. Phys. Chem. B, vol. 105, no. 5, pp. 1033 1040, Jan. 2001.

[13] X. Q. Qiu, G. S. Li, X. F. Sun, L. P. Li, and X. Z. Fu, "Doping effects of Co ions on ZnO nanorods and their photocatalytic properties," Nanotechnology, vol. 19, pp. 215703 , May 2008.

[14] R. Ullah and J. Dutta, "Photocatalytic degradation of organic dyes with manganese-dopeded $\mathrm{ZnO}$ nanoparticles," J. Hazard. Mater., vol. 156, no. 1-3, pp. 194-200, Aug. 2008.

[15] Q. Zhang, W. Fan, and L. Gao, "Anatase $\mathrm{TiO}_{2}$ nanoparticles immobilized on $\mathrm{ZnO}$ tetrapods as a highly efficient and easily recyclable photocatalyst," Appl. Catal. B: Environ., vol. 76, no. 1-2, pp. 168 173, Oct. 2007.

[16] S. Anandan, A. Vinu, K. L. P. S. Lovely, N. Gokulakrishnan, P. Srinivasu, T. Mori, V. Murugesan, V. Sivamurugan, and K. Ariga, "Photocatalytic activity of La-doped $\mathrm{ZnO}$ for the degradation of monocrotophos in aqueous suspension," J. Mol. Catal. A: Chem., vol. 266, no. 1-2, pp. 149-157, Apr. 2007.

[17] $\mathrm{D}$. $\mathrm{Li}$ and $\mathrm{H}$. Haneda, "Photocatalysis of sprayed nitrogen-containing $\mathrm{Fe}_{2} \mathrm{O}_{3}-\mathrm{ZnO}$ and $\mathrm{WO}_{3}-\mathrm{ZnO}$ composite powders in gas-phase," J. Photochem. Photobiol. A: Chem., vol. 160, no. 3, pp. 203-212, Aug. 2003.

[18] S. Ekambaram, Y. Iikubo, and A. Kudo, "Combustion synthesis and photocatalytic properties of transition metal-incorporated ZnO," J. Alloys Compd., vol. 433, no. 1-2, pp. 237-240, May 2007.

[19] H. F. Lin, S. C. Liao, and S. W. Hung, "The dc thermal plasma synthesis of $\mathrm{ZnO}$ nanoparticles for visible-light photocatalyst," J. Photochem. Photobiol. A: Chem., vol. 174, pp. 82-87, Aug. 2005.

[20] V. Kruefu, E. Peterson, C. Khantha, C. Siriwong, S. Phanichphant, and D. L. Carroll, "Flame-made niobium doped zinc oxide nanoparticles in bulk heterojunction solar cells," Appl. Phys. Lett., vol. 97, pp. 053302, Aug. 2010.

[21] V. Kruefu, C. Khantha, C. Liewhiran, and S. Phanichphant, "Flame-made Nb-doped zinc oxide nanoparticles for application in polymer solar cells," in Proceedings of the 2010 5th IEEE International Conference on Nano/Micro Engineered and Molecular Systems, Jan. 2010, pp. 65-69.

[22] V. Kruefu, C. Liewhiran, A. Wisitsoraat, and S. Phanichphant, "Selectivity of flame-spray-made $\mathrm{Nb} / \mathrm{ZnO}$ thick films towards $\mathrm{NO}_{2}$ gas," Sens. Actuators B: Chem., vol. 156, pp. 360-367, Aug. 2011.

[23] H. Sawada, R. Wang, and A. W. Sleight, "An electron density residual study of zinc oxide," J. Solid State Chem., vol. 122, no. 1, pp. 148-150, Feb. 1996.

[24] O. Carp, C. L. Huisman, and A. Reller, "Photoinduced reactivity of titanium dioxide," Prog. Solid State Chem., vol. 32, pp. 33-177, Nov. 2004.

[25] A. Sclafani and J. M. Hermann, "Influence of metallic silver and of platinum-silver bimetallic deposits on, the photocatalytic activity of titania (anatase and rutile) in organic and aqueous media," J. Photochem. Photobiol. A. Chem., vol. 113, pp. 118-188, May 1998.

[26] J. Yang, X. Zhang, C. Wang, P. Sun, L. Wang, B. Xia, Y. Liu, "Solar photocatalytic activities of porous Nb-doped $\mathrm{TiO}_{2}$ microspheres prepared by ultrasonic spray pyrolysis," Solid State Sci., 14, pp. 139-144, November, 2012.

[27] X. Li, X. Han, W. Wang, X. Liu, Y. Wang, and X. Liu, "Synthesis, characterization and photocatalytic activity of Nb-doped $\mathrm{TiO}_{2}$ nanoparticles," Adv. Mater. Res., vol. 455, pp. 110-11, Jan. 2012.

[28] J. A. Rodríguez and G. M. Fernández, Synthesis Properties and Applications of Oxide Nanomaterials. New York: John Wiley \& Sons, Inc., 2007, pp. 335-351. 
